\title{
207 Molecular MR-Imaging of myocardium using EP-3600, a collagen specific contrast agent: assessment of myocardial perfusion defects in a swine model
}

\author{
Elmar Spuentrup*1, Karl M Ruhl2, Rene M Botnar ${ }^{3}$, Andrea J Wiethoff4, \\ Alexandra Buhl ${ }^{2}$, Vincent Jacques ${ }^{5}$, Matthew T Greenfield ${ }^{5}$, \\ Gabriele A Krombach ${ }^{2}$, Rolf W Guenther ${ }^{2}$ and Peter Caravan ${ }^{6}$
}

Address: ${ }^{1}$ University of Cologne, Cologne, Germany, ${ }^{2}$ RWTH Aachen, Aachen, Germany, ${ }^{3}$ Technical University Munich, Munich, Germany, ${ }^{4}$ Philips Medical Systems, Best, The Netherlands, ${ }^{5}$ EPIX Pharmaceuticals, Lexington, MA, USA and ${ }^{6}$ Massachusetts General Hospital, Charlestown, MA, USA

* Corresponding author

from I th Annual SCMR Scientific Sessions

Los Angeles, CA, USA. I-3 February 2008

Published: 22 October 2008

Journal of Cardiovascular Magnetic Resonance 2008, I0(Suppl I):A68 doi:I0.1 I86/I532-429X-10-SI-A68

This abstract is available from: http://jcmr-online.com/content/I0/SI/A68

(c) 2008 Spuentrup et al; licensee BioMed Central Ltd.

\section{Background}

The non-invasive assessment of the haemodynamic significance of coronary artery disease is still challenging. Cardiac MR perfusion imaging during the first pass after i.v. administration of an extracellular contrast agents is limited by the spatial and temporal resolution achievable as well as by the artifacts seen in ultrafast MR-imaging. Moreover the patient must be stressed while being inside the magnet. Two injections of contrast are required, and a time consuming data analysis is necessary.

The use of molecular MR-imaging by means of a target specific contrast agent with perfusion dependent binding to myocardium may enable prolonged visualization of perfusion defects and thus may help to overcome limitations of currently used first pass extracellular MRI. EP3600 , a peptide-gadolinium hybrid, is a new Gd-containing molecular contrast agent which binds reversibly to myocardial collagen. It consists of a 15 amino acid peptide that is functionalized with three Gd-DOTA type chelates on the $\mathrm{N}$-terminus. In contrast to the compound EP-3533 recently reported [1,2], EP-3600 uses the DOTA chelator.
The aim of this study was to investigate the potential of EP-3600 for the assessment of myocardial perfusion defects in a swine model of coronary artery stenosis.

\section{Methods}

A significant coronary artery stenosis was modeled in 8 domestic swine using an undersized MR-compatible balloon positioned in the LAD as verified by X-ray angiography. Two animals died prior to contrast injection due to arrythmias. In 5 swine, high spatial resolution T1weighted gradient echo imaging was performed prior, 5, 20, 40 and 60 minutes after i.v. administration of 12.3 $\mu \mathrm{mol} / \mathrm{kg}$ EP-3600. Imaging parameter included a saturation-preparation prepulse (103 $\mathrm{ms}$ for each slice), cardiac triggering, $\mathrm{TR}=4.6 \mathrm{~ms}, \mathrm{TE}=1.4 \mathrm{~ms}$, flip angle $=12^{\circ}$, fieldof-view of $270 \times 270 \mathrm{~mm} 2$, matrix of $256 \times 256$ with an in-plane reconstructed voxel size of $1.05 \times 1.05 \mathrm{~mm} 2$, SENSE-factor 2.1, total imaging time for five $10 \mathrm{~mm}$ thick slices 21 seconds at a heart rate of 80 beats/minutes allowing for breath-hold imaging. Contrast was administered during stress induced by an infusion of $250 \mu \mathrm{mol} / \mathrm{kg} / \mathrm{min}$ adenosine. One further swine served as a control and received $0.05 \mathrm{mmol}$ of standard Gd-DTPA. Yb-DTPA was administered simultaneously in 5 pigs for comparison of myocardium/plasma ratios. 


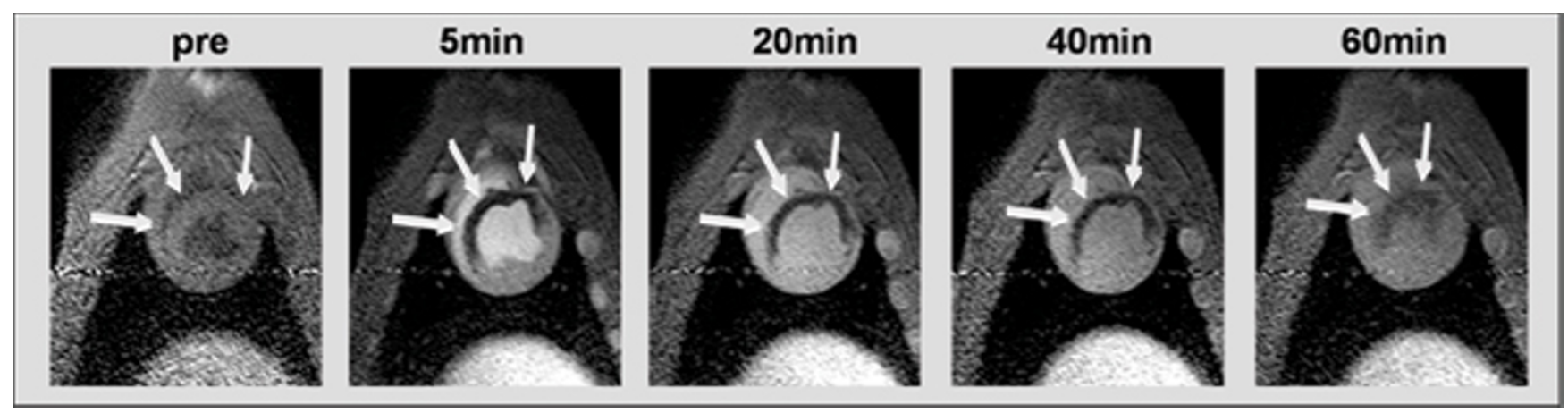

Figure I

Molecular MR-imaging of myocardial perfusion defect using EP-3600 and TI-weighted high spatial resolution gradient-echo imaging. The perfusion defect in the LAD territory is clearly seen (arrows). In this swine, the defect is readily visible up to 60 minutes after administration of EP-3600. Initial results of molecular MR-imaging of myocardial perfusion using a collagen-specific contrast agent are presented. This new agent enables prolonged, high contrast and high spatial resolution visualization of myocardial perfusion defects in a swine model of coroanry stenosis.

Images were subjectively assessed by two investigators (good contrast, and signal-to-noise (SNR) and contrastto-noise ratio (CNR) over time were calculated.

\section{Results}

Normal myocardium showed a significant SNR increase during the entire examination time. In all animals which received EP-3600 $(n=5)$, the perfusion defect in the LAD territory could be visualized with a high CNR for at least 20 minutes post contrast injection (Figure 1). A significant higher myocardium/plasma ratio was found for EP3600 compared to the control agent Yb-DTPA $(0.88 \pm 0.26$ vs $0.22 \pm 0.08$ respectively, $\mathrm{p}<0.01)$. In the control swine which received standard Gd-DTPA no perfusion defect was visible at 5 minutes post injection or at later time points.

\section{Conclusion}

EP-3600 is a new molecular MR-imaging contrast agent which binds to the myocardium and enables prolonged, high contrast and high spatial resolution visualization of myocardial perfusion defects.

\section{References}

I. Caravan P, Das B, Dumas S, Epstein F, Helm P, Jacques V, Koerner S, Kolodziej A, Shen L, Sun W, Zhang Z: Collagen targeted MRI contrast agent for molecular imaging of fibrosis. Angew Chem Int Ed in press.

2. Helm P, Caravan P, French BA, Dumas S, Jacques V, Shen L, Beyers R, Roy RJ, Kramer CM, Epstein F: Molecular MRI of post-infarct myocardial scar in mice using a collagen-targeted contrast agent. Radiology in press.

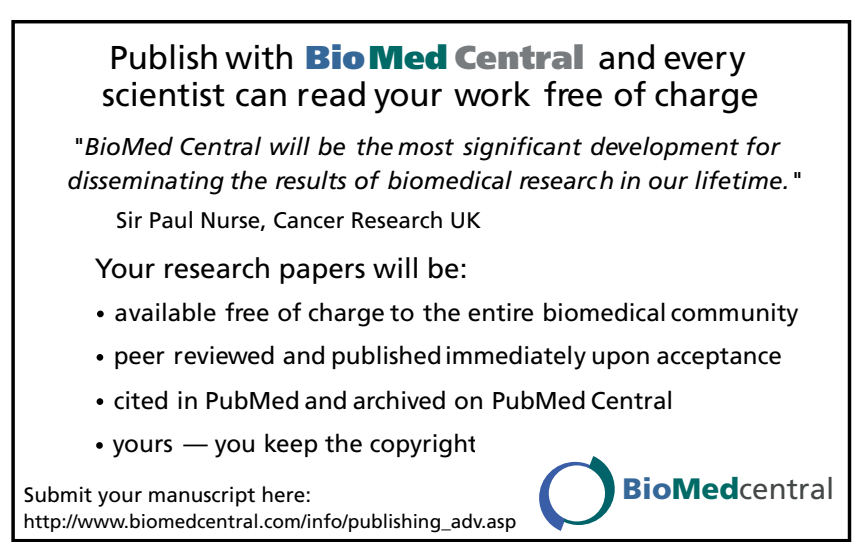

